\title{
Caracterização mecânica e morfológica de solados produzidos com resíduos de laminados de PVC da indústria calçadista
}

\author{
Mechanical and morphological characterization \\ of soles produced with PVC laminate waste \\ of the footwear industry
}

\author{
Ademir Anildo Dreger ${ }^{1}$, Luiz Antônio Barbosa ${ }^{2}$, Ruth Marlene Campomanes Santana ${ }^{3}$,
} Eduardo Luis Schneider ${ }^{4}$, Fernando Dal Pont Morisso ${ }^{5}$

\footnotetext{
${ }^{1}$ Mestre em Materiais e Processos Industriais, Universidade Feevale. e-mail: ademidreger@hotmail.com

${ }^{2}$ Mestre em Materiais e Processos Industriais, Universidade Feevale. e-mail: luizab@tca.com.br

${ }^{3}$ Docente do Departamento de Engenharia de Materiais da Universidade Federal do Rio Grande do Sul.

e-mail: ruth.santana@ufrgs.br

${ }^{4}$ Docente do Mestrado em Tecnologia de Materiais e Processos Industriais, Universidade Feevale.

e-mail: eduardoluis@ feevale.br

${ }^{5}$ Docente do Mestrado em Tecnologia de Materiais e Processos Industriais, Universidade Feevale.

e-mail: morisso@feevale.br
}

\begin{abstract}
RESUMO
A indústria de calçados emprega em seus produtos diversas matérias primas derivadas do setor de plásticos. Um dos mais utilizados é o laminado sintético de PVC, utilizado na construção de cabedais devido à grande versatilidade de cores, estampas e espessuras. O laminado é composto de PVC e de fibra têxtil, normalmente na proporção mássica de 60/40. O corte das peças gera uma grande quantidade de aparas que normalmente são descartadas ou depositadas em aterros sanitários ou ARIPs (Aterros de Resíduos industriais Perigosos). O presente trabalho avalia a viabilidade de incorporação destes resíduos em forma de pó em matriz de PVC virgem para uso em solados nas proporções de $0,5,15,25,35$ pcr (partes por cento de resina), bem como seu desempenho mecânico. Foram avaliadas propriedades físico-mecânicas com tração, dureza shore A e colagem, microscopia eletrônica de varredura (MEV) e espectroscopia no infravermelho (FTIR). Os resultados dos ensaios de dureza e tração demonstraram um decréscimo no desempenho na medida em que a concentração de resíduo no compósito aumentou. A força de colagem também apresentou queda na resistência final obtida pelo efeito pull out, confirmado pelas micrografias da superfície de fratura. Pode-se dizer que as misturas com resíduos de laminados em pó apresentam características aceitáveis, segundo as normas indicadas e os padrões especificados para a utilização como material para solado. Além disso, a incorporação deste resíduo diminui a quantidade de material descartado reduzindo o impacto ambiental.
\end{abstract}

Palavras-chave: PVC, compósitos, resíduos de laminado sintético, reciclagem

\section{ABSTRACT}

The footwear industry uses in its products various raw materials derived from the plastics sector. One of the most used is the synthetic PVC laminate, used in the construction of leather because of the great versatility of colors, prints and thicknesses. The laminate is composed of PVC and textile fiber, usually in the mass ratio of 60/40. Cutting of parts generates a large amount of shavings that are normally discarded or deposited in landfills or ARIPs (Hazardous Industrial Waste Landfills). The present work evaluates the feasibility of incorporating these residues in the form of powder in virgin PVC matrix for use in soils in proportions of $0,5,15,25$, 35 pcr (parts per cent of resin), as well as their mechanical performance. Physical-mechanical properties with traction, shore A hardness and bonding, scanning electron microscopy (SEM) and infrared spectroscopy (FTIR) were evaluated. The results of the hardness and tensile tests showed a decrease in performance as the concentration of residue in the composite increased. The bond strength also showed a decrease in the final resistance obtained by the pull out effect, confirmed by fracture surface micrographs. Mixtures with powdered laminate residues may be said to have acceptable characteristics, in accordance with the standards indi- 
cated and the standards specified for use as flooring material. In addition, the incorporation of this residue reduces the amount of material discarded reducing the environmental impact.

Keywords: PVC, composites, synthetic laminate waste, recycling

\section{INTRODUÇÃO}

Nos dias de hoje é fato que o desenvolvimento tecnológico ambientalmente correto é cada vez mais necessário. Neste sentido, a possibilidade de alterar a composição e as propriedades físicas e químicas dos materiais é um aspecto intimamente ligado à aplicação dos mesmos, de maneira a atender tanto a exigências tecnológicos quanto ambientais. No entanto, mesmo que avanços científicos venham sendo obtidos nas áreas de desenvolvimento acadêmico, como sínteses e degradação de materiais, muito ainda há para ser feito na área de materiais. Deste modo, uma área interessante é a dos materiais poliméricos, que podem ser combinados entre si ou com outros materiais de forma a gerar misturas poliméricas, copolímeros e compósitos.

O PVC é um dos polímeros que mais se aplica à preparação de compósitos e um dos que mais aceita aditivos em suas formulações. Neste sentido, é o segundo polímero termoplástico mais utilizado no Brasil, com um consumo aparente de 1.1 milhão de toneladas no ano de 2011 sendo que um consumo per capita de aproximadamente de $5,6 \mathrm{~kg} / \mathrm{hab}$ [1]. Na literatura podem ser encontrados trabalhos sobre a preparação e caracterização de compósitos de PVC com celulose microcristalina proveniente de resíduos de algodão [2], com oligômeros poliédricos como o POSS [3], com poliuretano [4], com partículas de bambu [5], com partículas de madeira [6] e com grafeno [7], dentre outros. No entanto, sobre a preparação de compósitos com laminados sintéticos de PVC, não foram encontrados trabalhos na literatura.

O PVC é o segundo termoplástico mais consumido no mundo, o que pode ser justificado pela sua versatilidade. O PVC pode ter suas características variadas em função de sua aplicação desde rígido até o extremamente flexível e pode passar pelos mais variados processos de moldagem, como injeção, extrusão, calandragem e espalmagem, para citar alguns [8], aceitando para tal, a adição de inúmeros aditivos [9]. Neste sentido, a participação do PVC na fabricação de varas de pesca, peças de vestuário, brinquedos, faixas de propaganda, calçados e muitas outras, é bastante substancial [10,11]. A literatura [12] sugere que até 2025 a quantidade de PVC inserida no fluxo de consumo mundial crescerá em mais de 50\%. Enquanto dados do Instituto do PVC [1] demonstram que em 2009 a indústria de calçado consumiu 6,7\% da resina de PVC preparada no país e a resina destinada à preparação de laminados e espalmados correspondeu a $13 \%$ da produção do país.

A literatura [13] sugere uma tendência de substituição de laminado de poliuretano (PU) por laminados de PVC como forma de baratear custos do setor calçadista e aponta que os materiais laminados poderiam ser encarados como commodities. De acordo com a norma NBR 13.889 [14], materiais utilizados para a construção de partes de calçados podem ser identificados como laminado sintético, sendo este, um material polimérico que pode ou não estar aplicado sobre um substrato. Este substrato pode ser tecido, não tecido, malha ou papel e no caso dos laminados de PVC, normalmente são utilizados substratos têxteis.

O objetivo deste trabalho é desenvolver compósitos de PVC com resíduos de laminados sintéticos na forma de pó moído nas proporções de Lam 5, 15, 25, 35 pcr sobre a resina virgem de PVC para aplicação em solados de calçados avaliando a força de colagem, a tração, dureza shore A, e a analise morfológica.

\section{MATERIAIS E MÉTODOS}

\subsection{Materiais}

Para a realização deste trabalho foi utilizada uma resina de PVC Braskem K65, off grade. O plastificante principal utilizado foi DOP (bis-(2-etil-exil)ftalato) com teor de ésteres mínimo de 99,4\%, e como plastificante secundário foi utilizado o óleo de soja epoxidado. Como estabilizante térmico foi utilizado o Plastabil ICZ-221 a base da Ca/Zn e o acido esteárico granulado como lubrificante externo. Como corante dos compósitos foi utilizado o máster pigmentador MBU Preto 48/1. Os resíduos de laminado de PVC utilizado na preparação dos compósitos possuía como substrato têxtil uma malha de algodão e foram originados no processo de corte de cabedais para calçados. Estes resídudos não foram segregados por nenhum tipo de identificação ou cor. Em sua composição integral apresentou densidade aparente igual a $0,1127 \mathrm{~g} / \mathrm{cm}^{3}$. Depois de moídos e micronizados, sem identificação ou seleção de cor, o pó apresentou densidade aparente igual a $0,4197 \mathrm{~g} / \mathrm{cm}^{3}$, ambas medidas foram realizadas de acordo com a norma ASTM D-1895 [15]. 


\subsection{Processamento}

Após o processo de corte, os laminados de PVC foram moídos em um moinho granulador de facas modelo MGHS 15-300 fabricado pela Seibt. O material particulado apresentou diâmetro de aproximadamente $8 \mathrm{~mm}$ e levado ao micronizador com discos de aço em rotação contraria, gerando pó com partículas de aproximadamente $1 \mathrm{~mm}$ x $6 \mathrm{~mm}$ de comprimento. O pó obtido de laminado foi incorporado em diferentes teores: 0 (padrão), 5 (Lam5), 15 (Lam15), 25 (Lam25) e 35 (Lam35) pcr substituindo a resina básica de PVC. A partir desta etapa, todos os compostos foram pesados, misturados e estabilizados por $24 \mathrm{~h}$.

A homogeneização final foi realizada em kneader, marca JKM, modelo DK5 com capacidade para 7 kg cada mistura. A extrusora utilizada, da marca Granoplast, modelo monorosca EXT 65KE, com rosca transportadora de $600 \mathrm{~mm}$, com $\mathrm{L} / \mathrm{D}=25: 1$ onde ocorre a homogeneização final do composto. A temperatura utilizada na extrusora foi de $140^{\circ} \mathrm{C}$ e $150^{\circ} \mathrm{C}$ no cabeçote. $\mathrm{O}$ espaguete obtido pela extrusão foi seccionado no formato de grânulos (pellets). A velocidade de processamento e de corte foi de 40 RPM.

Para moldagem por injeção dos corpos de prova foi utilizada uma injetora modelo 750/110 ITR II VS do fabricante 3R do Brasil, sistema rosca pistão com fechamento pneumático com pressão de $8 \mathrm{kgf} / \mathrm{cm}^{2}$. As condições de injeção dos corpos de prova foram: temperatura zona de alimentação: $150^{\circ} \mathrm{C}$; de plastificação: $155^{\circ} \mathrm{C}$; de dosagem: $160^{\circ} \mathrm{C}$; pressão de injeção: 45 bar; temperatura do molde: $60^{\circ} \mathrm{C}$; resfriamento $45 \mathrm{~s}$. Todos os compostos foram injetados na mesma injetora e nas mesmas condições determinadas de temperatura e pressão. O processo de injeção resultou em peças na forma de placas com dimensões de $250 \mathrm{~mm}$ x 100 mm x 6 mm, como mostrado na Figura 1.

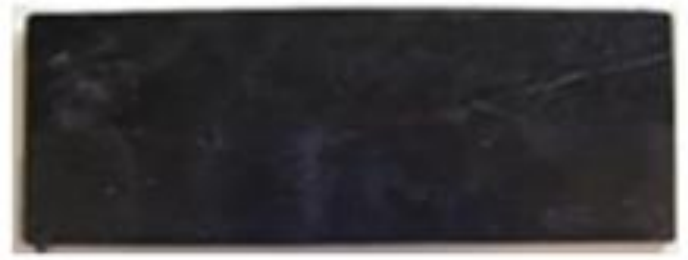

Figura 1: Placa de compósito Lam 35 injetada, a partir da qual foram preparados os corpos de prova desta formulação. A placa original apresenta dimensões de $250 \mathrm{~mm}$ x $100 \mathrm{~mm}$ x $6 \mathrm{~mm}$.

\subsection{Caracterização}

As análises de infravermelho (FTIR) foram realizadas em equipamento Perkin-Elmer Spectrum Two com acessório de refletância universal total atenuada (UATR), a partir de um fragmento de cada amostra, coletado aleatoriamente nos corpos de prova. As análises foram realizadas após as amostras serem submetidas aos ensaios mecânicos. Ainda, fragmentos dos corpos de prova foram submetidos ao envelhecimento forçado em câmara de intemperismo Equilan, modelo EQUV/Spray. Os fragmentos foram expostos durante 4 horas em radiação UVA e UVB, analisados por infravermelho, expostos mais 4 horas e novamente analisados por infravermelho. As duas faixas de radiações, UVA - $340 \mathrm{~nm}(0,89 \mathrm{~W} / \mathrm{m} 2 / \mathrm{nm})$ e UVB - $313 \mathrm{~nm}(0,71$ $\mathrm{W} / \mathrm{m} 2 / \mathrm{nm}$ ) foram produzidas por 8 lâmpadas de $40 \mathrm{~W}$ cada, dispostas em dois grupo sde 4 unidades, cada um atuando em uma faixa de radiação.

Os compósitos de PVC/laminados de PVC foram caracterizados através de suas propriedades físicas e mecânicas. O teste de dureza foi realizado segundo a norma DIN 53505 [16] em um durômetro digital Bareiss, modelo HPE-A. Para cada amostra, de padrão e compósitos, foram preparados 10 corpos de prova na forma de placas circulares de $67 \mathrm{~mm}$ de diâmetros e $10 \mathrm{~mm}$ de altura. O teste de tração e alongamento foi realizado segundo a norma DIN 53504 [17] em uma máquina universal de ensaios, modelo DL 500, EMIC e velocidade de $100 \mathrm{~mm} / \mathrm{min}$. Os corpos de prova são cortados de acordo com o tipo $\mathrm{S} 1$ descrito na norma, com formato de gravata borboleta, medindo $115 \mathrm{~mm}$ de comprimento e a espessura do corpo de prova é de 4 $\mathrm{mm}$. O valor orientativo para o PVC compacto é de no mínimo $0,8 \mathrm{kgf} / \mathrm{mm}^{2}$ na tração e $300 \%$ de alongamento, conforme a referência [17].

O processo de colagem foi realizado segundo procedimento utilizado no laboratório de uma grande empresa do ramo, que estabelece o procedimento padrão de ensaio de colagem com adesivo de poliuretano. Para cada material foram preparadas dez amostras cortadas com dimensões de 150 x $25 \mathrm{~mm}$. As superfícies foram limpas com acetona e deixadas secar ao ar por 7 minutos, após aplicado o adesivo nas duas superfícies a serem coladas, cada tira de compósito foi deixada secar ao ar por 16 minutos. Os corpos de prova foram reativados a $70^{\circ} \mathrm{C}$ e prensados durante 12 segundos com $6 \mathrm{kgf} / \mathrm{cm}^{2}$ de pressão e climatizadas por $24 \mathrm{~h}$ para a abertura de colagem. 
As amostras dos compósitos de PVC para a análise morfológica por microscopia eletrônica de varredura $(\mathrm{MEV})$ foram preparadas por fratura criogênica com nitrogênio líquido. Em seguida, foram metalizadas com uma fina camada de ouro em equipamento metalizador Denton Vacuum Desk V, Denton Vacuum, Moorestown, USA, conforme procedimento padrão. As análises morfológicas de MEV foram realizadas em equipamento JOEL, Modelo JSM-6510LV, com software SEM Control User Interface Ver. 3.01, utilizando-se radiação de tungstênio da ordem de $5 \mathrm{kV}$ e por detecção de elétrons secundários. Ambos os equipamentos disponíveis no Laboratório de Estudos Avançados em Materiais da Universidade Feevale.

\section{Resultados e discussão}

Na Figura 2, à esquerda, são apresentados os espectros de infravermelho (FTIR) dos diferentes compósitos preparados com resíduo de laminado sintético de PVC e à direita, os espectros do compósito Lam 35 depois da irradiação com UVA e UVB em 4 e 8 h.
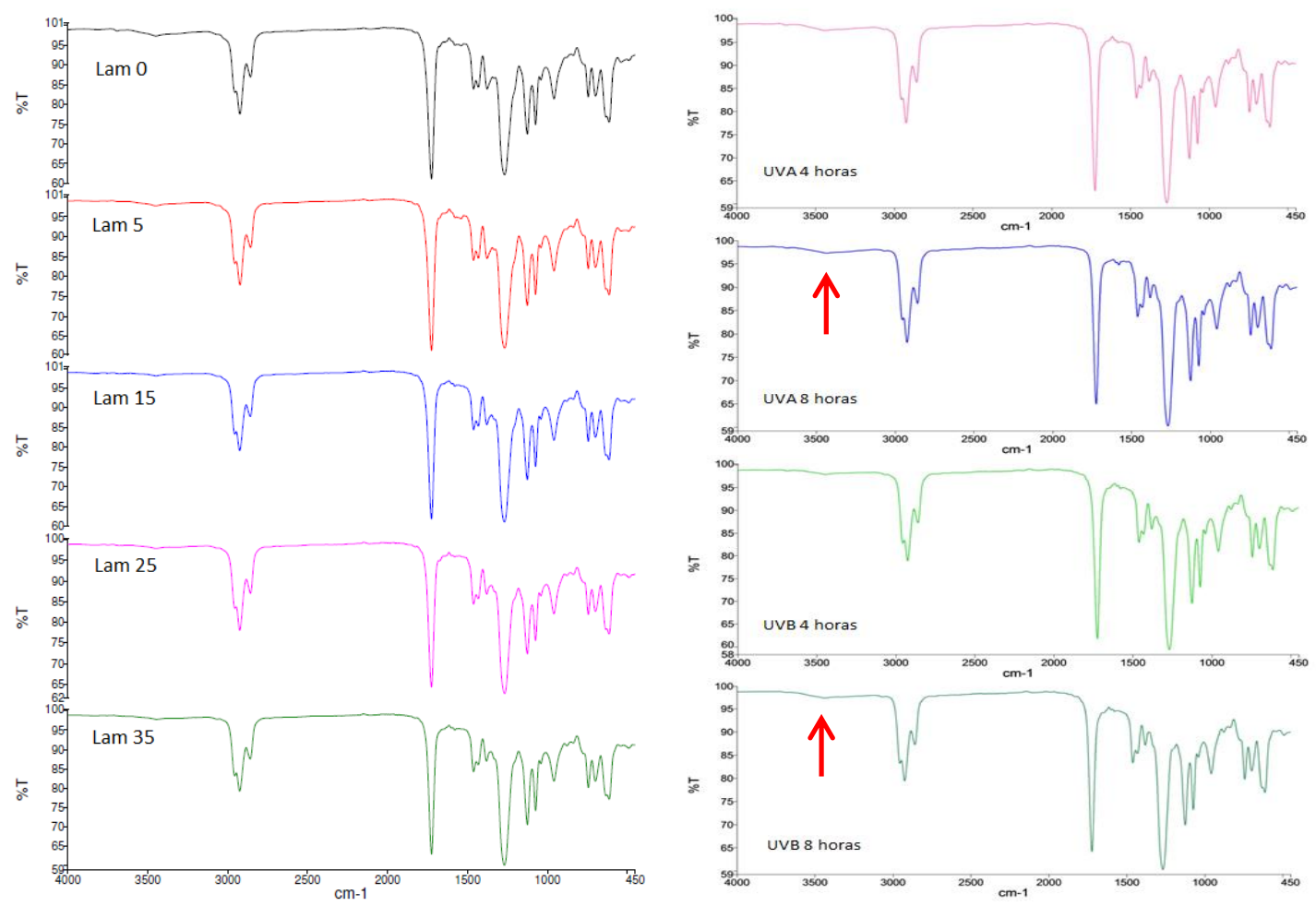

Figura 2: Esquerda: espectros de infravermelho dos compósitos Lam 0 a Lam 35; Direita: espectros de infravermelho da amostra Lam 35 exposta à radiações UVA e UVB durante 4 e 8 horas.

Nos espectros de FTIR das amostras sem e com diferentes teores de carga, na Figura 2 à esquerda, é possível observar que todos apresentam as mesmas bandas carcaterísticas, sem mostrar diferenças significativas entre elas. No conjunto à direita, a Figura 2 apresenta os espectros de FTIR da amostra Lam 35 após irradiação com UVA e UVB. Nota-se que, especialmente com maior tempo de exposição (8h) em ambas as radiações, os espectros apresentam uma pequena banda formada entre 3000 e $3700 \mathrm{~cm}-1$, inicialmente correspondente a grupos hidroxila (apontados com setas na Figura 2). A presença desta banda pouco pronunciada não foi considerada como indicativo de processo de degradação ou algum outro processo de alteração no material, pois este detalhe aparece nos espectros de todas as amostras antes e depois da irradiação e foi considerado não significativo uma vez que a penetração da radiação UV em polímero é bastante superficial, da ordem de micrometros, devido à baixa energia da masma [18]. Esta observação é corroborada pela exposição de um compósito de PVC com aplicação na área da saúde, que apresentou pequenas variações indicativas de alterações não relevantes à aplicação do material quando este foi irradiado por até 240 horas com radiação UVB (330 a $320 \mathrm{~nm})$ [19].

Considerando, então, que não há alteração relevante à estrutura do polímero causada por irradiação UV e que aspectos mecânicos apresentam maior relevância em função da aplicação como solado, a Figura 3 apresenta os resultados de dureza na escala Shore A. Pode-se observar um pequeno decréscimo no valor da 
propriedade com o aumento do teor de resíduo (78 a 71 Shore A) e este efeito pode ser decorrente da menor dureza da carga incorporada à mistura. Outro aspecto a ser considerado diz respeito ao aumento do teor de plastificante, com efeito apontado na literatura [20-22]. A incorporação do plastificante em uma matriz polimérica conduz à alteração das propriedades mecânicas do polímero puro e uma das propriedades que sofre alteração é a dureza. No caso dos compósitos preparados neste trabalho, à resina virgem de PVC utilizada para a preparação dos mesmos, foram adicionados diferentes percentuais de laminado sintético de PVC, que já continham em sua formulação, plastificante. Assim a diminuição da dureza Shore A dos compósitos de PVC/laminado de PVC pode ser atribuída à incorporação de plastificante proveniente do resíduo laminado, uma vez que em todas as formulações, o único parâmetro alterado foi a relação entre a quantidade de resina virgem e a quantidade de resíduo laminado. Também é importante destacar que mesmo sofrendo decréscimo na dureza, os valores obtidos não ultrapassaram os valores de referência e não impedem a utilização de qualquer dos compósitos como material para solado. O valor orientativo para o $\mathrm{PVC}$ é de 30 à 95 Shore $\mathrm{A}$, conforme a norma DIN 53505 [16].

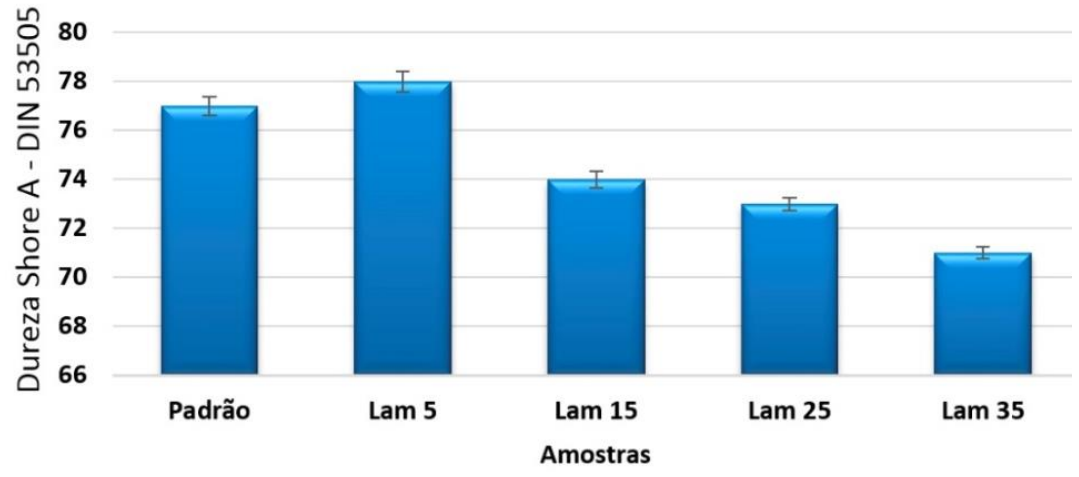

Figura 3: Dureza Shore A das amostras avaliadas.

A Figura 4 apresenta os resultados do ensaio de resistência à tração na ruptura das amostras sem e com os diferentes teores de resíduo, onde observa-se um decréscimo do valor da propriedade na medida em que aumenta o teor de carga. Este resultado está de acordo com a literatura que descreve que a resistência à tração está vinculada à qualidade da interface carga/matriz [23]. Neste caso, verifica-se um comportamento convergente entre as propriedades quanto à incorporação do laminado. Neste sentido, este resultados poderia estar indicando pouca interação da matriz polimérica com a fibra têxtil de do suporte do laminado conduzindo, desta forma, em um menor desempenho mecânico. Por outro lado, também são encontrados resultados divergentes na literatura [20], como em compósitos de PVC com fibras de bananeira, nos quais o aumento do percentual de fibra no compósito, levou a um aumentou a resistência à tração. No entanto, a divergência neste caso está relacionada à fibra de bananeira, como aponta o autor, que apresenta ancoragem mecânica mais pronunciada e aumenta a resistência à tração. Cabe salientar que mesmo que com uma queda nos valores de tração, estes não atenderam em sua integra a especificação de $0,8 \mathrm{kgf} / \mathrm{mm}^{2}$ na tração, conforme a norma DIN 53504 [17].

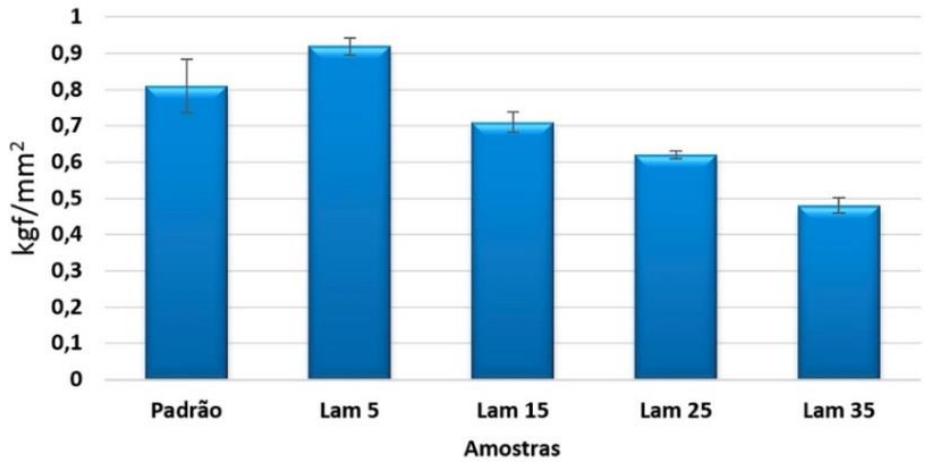

Figura 4: Variação da resistência à tração de acordo com a variação de incorporação de laminado na resina virgem. 
Na Figura 5 são mostrados os resultados do ensaio de deformação na ruptura, realizado conforme a norma DIN 53504 [17] e onde é possível observar um pequeno aumento no valor da propriedade com relação ao padrão. Vale mencionar que todos os compósitos apresentaram comportamento dentro do considerado aplicável ao setor calçadista, que é de até $300 \%$ de alongamento [17].

Efeito semelhante pode ser encontrado na literatura [20,21] e sugere que materias compósitos com uma pouca interação química entre uma carga de reforço e a matriz polimérica tendem a resistir menos à tração e a romper-se prematuramente com relação ao alongamento. Este fenômeno é conhecido como efeito pull out. Há de se considerar que uma carga de reforço deve impor melhores características mecânicas a uma matriz polimérica, mas também que sistemas compósitos são sistemas complexos e que a alteração de uma propriedade deve levar a alteração em outro comportamento. Neste caso, é sugerido que a dureza diminui em decorrência de um possível aumento de falhas impostas pela presença da carga que não interagem bem com a matriz polimérica ou por aumento da quantidade de plastificante proveniente da adição de laminado sintético e que a resistência à tração também diminui devido a uma proposta semelhante. Assim, faz sentido que, embora todos os compósitos paresentem valores superiores ao do material de referência, a ruptura ocorra cada vez mais cedo na medida em que se aumenta o teor de resíduo de laminado sintético de PVC. Por outro lado o que se observou foi um aumento inicial da propriedade, com posterior redução na medida em que se aumentou o teor de laminado. Então, é possível pensar que, num primeiro momento, a carga têxtil esteja agindo como reforço real, pois a incorporação de 5 pcr de laminado promove aumento do valor da propriedade e nas duas propriedades mecânicas descritas anteriormente. No entanto, na medida em que mais laminado é incorporado, o efeito da adição de plastificante proveniente da carga de resíduos de PVC pode sobrepor-se aos efeitos do teor de fibra têxtil e, assim, gradativamente reduz-se o valor destas propriedades. A literatura fundamenta esta proposta com a utilização de outras cargas como, por exemplo, a celulose microcristalina [2].

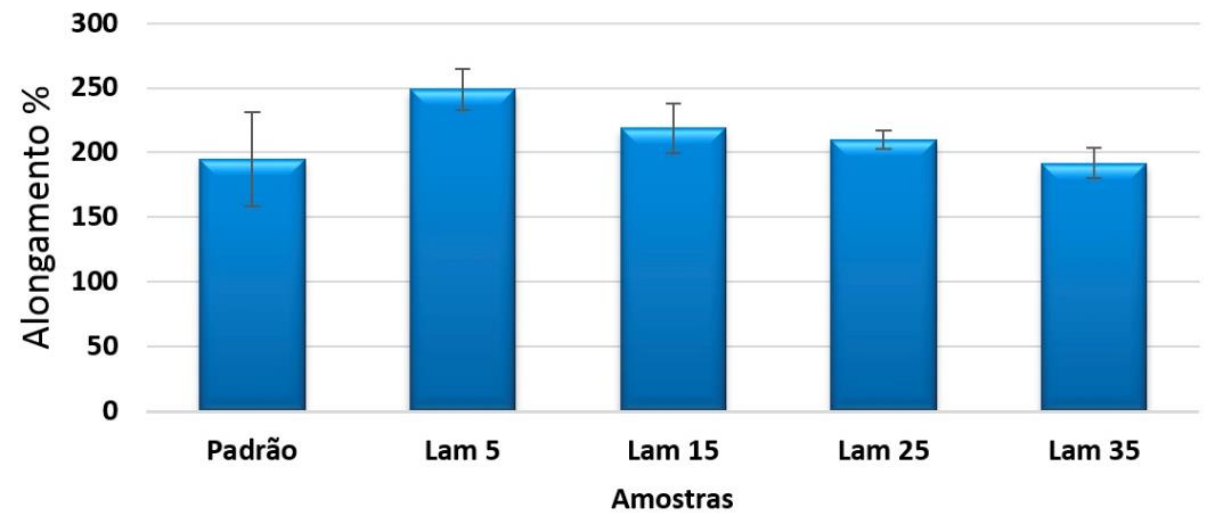

Figura 5: Variação de alongamento na ruptura de acordo com a variação de incorporação de laminado na resina virgem.

Uma outra propriedade mecânica avaliada foi a resistência ao descolamento (força de colagem), cujos resultados são descritos na Figura 6, que demonstram que as amostras com carga apresentaram resultados similares ao do branco. Exceção foi o composto com maior teor de carga (Lam35), cujo valor foi menor que o do branco. Assim, a incorporação de até 25 pcr (amostra Lam 25) além de manter as propriedades dentro de valores pouco melhores que os de referência, tornando o material aplicável ao fim desejado, ainda permite que $25 \%$ menos de resina virgem seja incorporada na formulação e que $25 \%$ menos de resíduo seja descartado, trazendo benefício econômico e ambiental ao processo. A amostra Lam 35 apresentou resistência mínima (no limite do valor de orientação) ao descolamento, apesar de o desvio padrão das medidas garantir a possiblidade de aplicação. O motivo desta variação pode ser o teor de plastificante, que cresce com o aumento da quantidade de resíduo ou o próprio teor de carga no compósito, no entanto, não foi investigada a causa desta diferença, pois como mencionado, mesmo com redução na resistência ao descolamento, o material atende o parâmetro de referência utilizado na indústria.

A Figura 7 apresenta uma micrografia da amostra Lam 0, padrão. Nesta micrografia é possível observar a superfície do corpo de prova sem bolhas ou falhas, isto é, somente com o estriamento na superfície devido à fratura criogênica (realizada em temperatura de nitrogênio líquido). Não é observada nenhuma fibra de carga inserida na matriz polimérica. Este aspecto morfológico mostra-se semelhante aos encontrados na literatura $[2,20,21]$. 


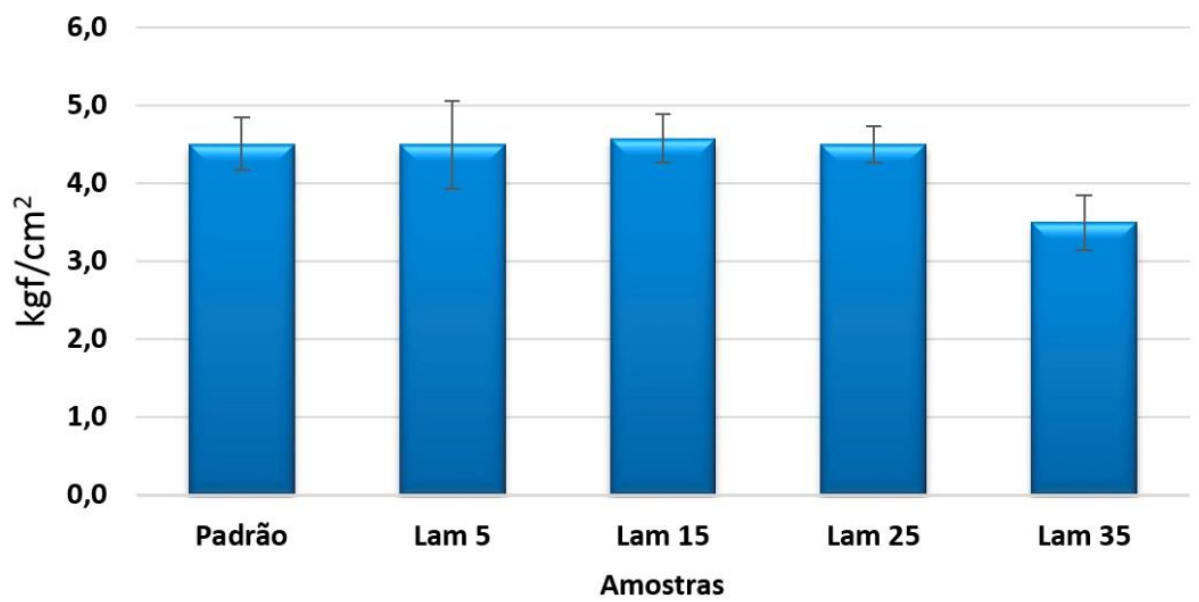

Figura 6: Resistência ao descolamento de acordo com a variação de incorporação de laminado na resina virgem.

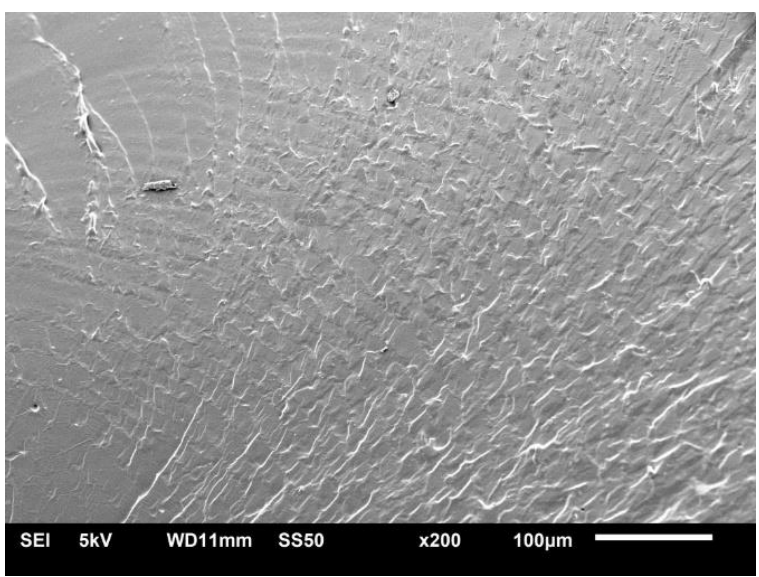

Figura 7: Micrografia da amostra Lam 0, padrão.

A Figura 8 apresenta uma micrografia da amostra Lam 5, na qual é possível observar, além das estrias provenientes da fratura criogênica, fibras emergindo da superfície, bem como alguns orifícios ou canais que alojam estas fibras. A presença de orifícios deve-se, provavelmente, a ausência da fibra em razão do processo de tração na fratura, efeito pull out [24].

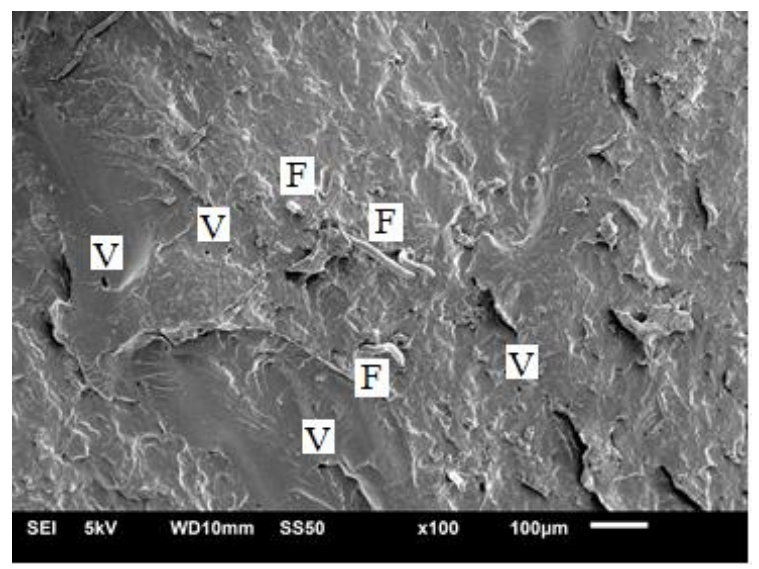

Figura 8: Micrografia da amostra Lam 5, exibindo estrias de fratura criogênica e fibras emergentes na superfície, bem como orifícios vazios provenientes da ausência de fibras (letras F, Fibra; letras V, Vacância). 
A Figura 9 apresenta micrografias das amostras Lam 15, 25 e 35. Nestas micrografias podem ser observadas as vacâncias e as fibras expostas nos compósitos. Com já foi exposto, a literatura descreve esta vacância entre fibra e matriz polimérica como descolamento e chama de efeito pull out [24]. Este comportamento pull out também foi identificado como uma adesão deficiente entre carga e matriz nos compósitos de PVC e farinha de madeira [25]. Nesse sentido, foi observado por microscopia eletrônica de varredura que em compósitos de PVC com fibra de sisal e diferentes plastificantes, quando este último é poliéster líquido, a interação física da fibra com a matriz polimérica foi menor do que quando utilizado plastificante sólido. Neste contexto a pouca interação física entre a matriz polimérica e a fibra têxtil proveniente do laminado pode ser observada na Figura 9 (D). Este observação demonstra que uma maior interação e consequente adesão fibra/matriz contribuem para o desempenho mecânico observado pelos compósitos PVC/pó de madeira. Desta forma, em decorrência das características mecânicas apresentadas pelos compósitos preparados com laminado sintético de PVC, é possível admitir que as fibras do suporte do laminado de PVC tendem a um comportamento predominantemente de enchimento e não de reforço, uma vez que se observa na micrografia da Figura 9 (D) um afastamento entre a matriz polimérica e a fibra.

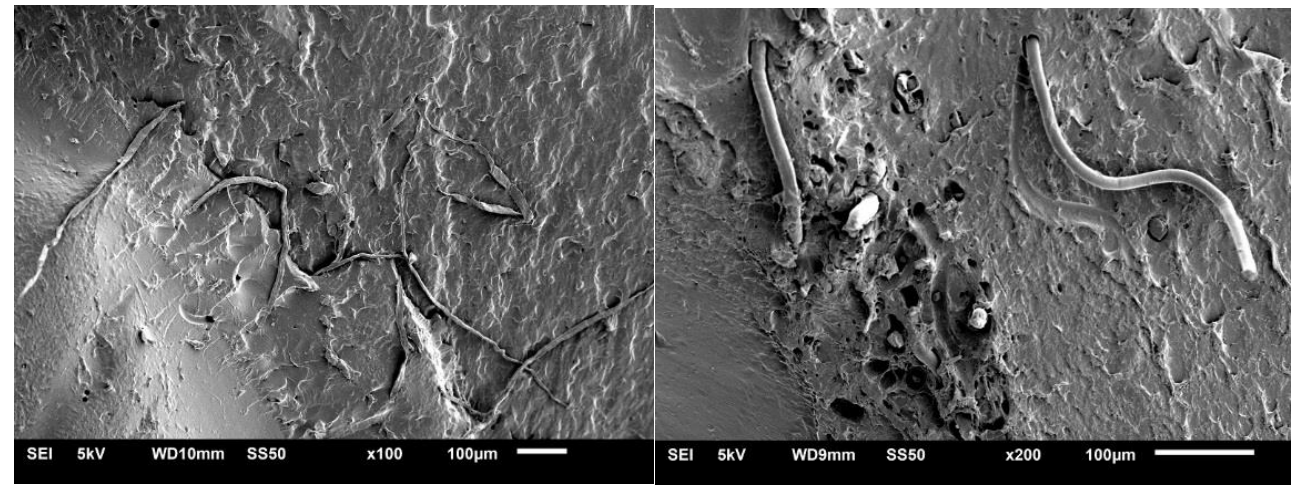

(A)

(B)

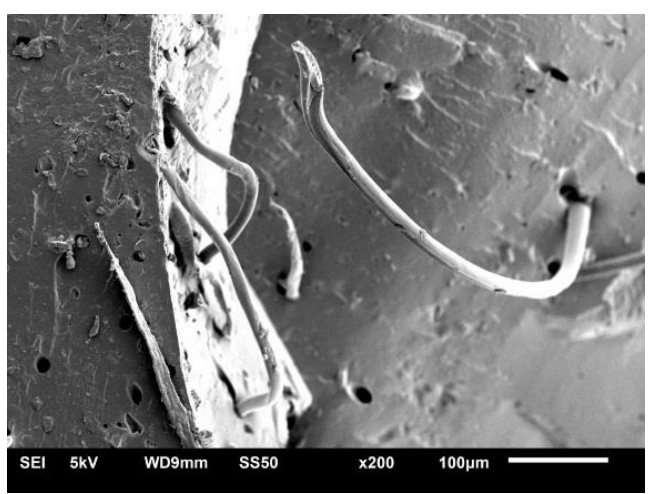

(C)

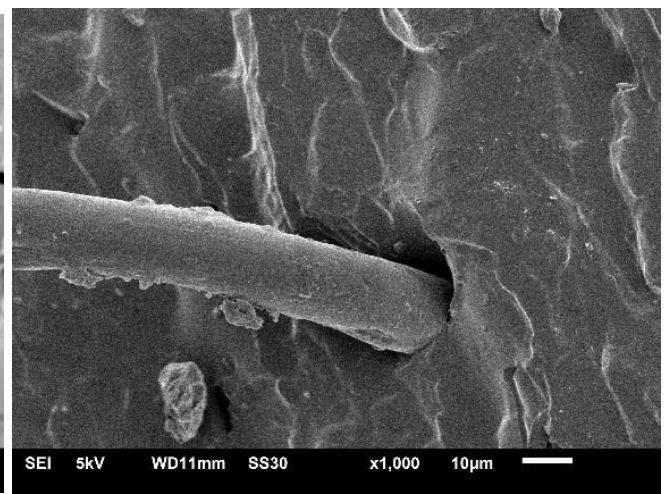

(D)

Figura 9: Micrografia da amostra Lam 15 (A), Lam 25 (B) e Lam 35 (C) exibindo estrias de fratura criogênica e fibras emergentes na superfície, bem como orifícios vazios provenientes da ausência de fibras. A micrografia (D) mostra, com aumento de 1000 vezes, o detalhe da pouca aderência da matriz polimérica à fibra têxtil.

\section{CONCLUSÕES}

Este trabalho teve como objetivo avaliar a influência da incorporação de diferentes percentuais de laminado de PVC moído, ao composto de PVC utilizado na fabricação de solados para calçados e as principais conclusões encontram-se a seguir apresentadas. Foram preparadas fórmulas com diferentes quantidades de laminado moído variando entre 5 e 35 pcr de resina virgem. O que permite pensar na aplicação destes compósitos como matéria prima para a fabricação de solados é que nenhuma propriedade revelou valor fora dos limites para a aplicação indicada.

Os compósitos, de maneira geral, apresentaram boas propriedades físico-mecânicas e demonstraram bom potencial para serem utilizados na fabricação de solados. O compósito Lam 25 particularmente, apresenta vantagens econômicas e ambientais sobre os outros, admitindo a incorporação de 25 pcr de laminado moído ao composto base de PVC, o que permite a redução de 25 partes sobre 100 a quantidade de resina virgem 
e consequentemente, que muito menos resíduo de laminado de PVC seja conduzido aos aterros. No entanto, o composto Lam35, que apresentou valores inferiores em todas os parâmetros avaliados, também atende os critérios de referência e poderia ser utilizado à finalidade proposta.

Sobre a metodologia de preparação dos compósitos pode-se concluir que o processo de moagem, micronização e mistura com o composto base de PVC para posterior extrusão, mostrou-se efetivo para a preparação dos compósitos, que podem ser processados por injeção para a preparação de solados. Assim, a principal conclusão a que se pode chegar com este trabalho é a viabilidade de se incorporar resíduos de laminado de PVC ao composto base de PVC utilizado na fabricação de solados. Também, a possibilidade de preparação e aplicabilidade dos compósitos apresenta-se como uma alternativa tecnológica e ambientalmente correta para a fabricação de solados de PVC.

\section{BIBLIOGRAFIA}

[1] INSTITUTO DO PVC (Brasil), http://www.institutodopvc.org. Acessado em maio de 2017.

[2] CHUAYJULJIT, S., SU-UTHAI, S., CHARUCHINDA, S., "Poly(vinyl chloride) film filled with microcrystalline cellulose prepared from cotton fabric waste: properties and biodegradability study", Waste Management \& Research, v. 28, pp.109-117, 2010.

[3] STERZYńSKI, T., TOMASZEWSKAB, J., ANDRZEJEWSKIA, J., et al., Evaluation of glass transition temperature of PVC/POSS nanocomposites, Composites Science And Technology, v. 117, pp.398-403, 2015.

[4] HEZMA, A.M., Elashmawiab, I.S., RAJEH, A., et al. "Change Spectroscopic, thermal and mechanical studies of PU/PVC blends", Physica B: Condensed Matter, v. 495, pp.4-10, 2016.

[5] BAHARI, S. A., KRAUSE, A. "Utilizing Malaysian bamboo for use in thermoplastic composites", Journal Of Cleaner Production, v. 110, pp.16-24, 2016.

[6] PULNGERN, T., CHITSAMRAN, T., CHUCHEEPSAKUL, S., et al., "Effect of temperature on mechanical properties and creep responses for wood/PVC composites", Construction And Building Materials, v. 111, pp.191-198, 2016.

[7] WANG, H., XIE, G., FANG, M., et al. "Mechanical reinforcement of graphene/poly(vinyl chloride) composites prepared by combining the in-situ suspension polymerization and melt-mixing methods", Composites Part B: Engineering, v. 113, pp.278-284, 2017.

[8] SOUZA, M., RODOLFO J.A., PESSAN, L.A., "Nanocompósitos de poli (cloreto de vinila) (PVC) / argilas organofílicas", Polímeros: Ciência e Tecnologia, v. 16, n. 4, pp.257-262, 2006.

[9] SILVA, R.P., MAULER, R.S., OLIVEIRA, R.V.B., et al., "Avaliação da Morfologia e Propriedades Termo-Mecânicas em Nanocompositos de PVC", In: Anais Programa de Pós Graduação em Ciência de Materiais da Universidade Federal do Rio Grande do Sul, Porto Alegre, 2010.

[10] DANIELS, P.H. "A Brief Overview of Theories of PVC Plasticization and Methods Used to Evaluate PVC-Plasticizer Interaction”, Journal of Vinyl \& Additive Technology, v. 15, n. 4, pp.219-223, 2009.

[11] GRIZZO, L.H., HAGE JUNIOR, E., LAURINI, R.V., "Desenvolvimento de PVC Reforçado com Fibras de Vidro Longas para Fabricação de Produtos Moldados", Polimeros: Ciência e Tecnologia, v. 21, n. 5, pp.369-375, 2011.

[12] KELLY, A.L."Recycling of uPVC Window Profile Waste", Journal of Vinyl \& Additive Technology, v. 11, n. 3, pp.119-226, 2005.

[13] ARBO, R.H. Estratégia de desenvolvimento de produto para empresas do arranjo produtivo local de calçados do vale do Rio do Sinos: estudo do caso dos laminados sintéticos de poliuretano. Dissertação de M.Sc., Pontifícia Universidade Católica do Rio Grande do Sul, Porto Alegre, 2006.

[14] ASSOCIAÇÃO BRASILEIRA DE NORMAS TÉCNICAS (ABNT). Construção Superior do Calçado Laminados Sintéticos - Terminologia: NBR 13889, Rio de Janeiro, outubro 2005. 6p.

[15] AMERICAN SOCIETY FOR TESTING AND MATERIALS (ASTM). Standard Test Methods for apparent density, bulk factor and pourability of plastic material: ASTM D1895 - 96 (Reapproved 2010), Pennsylvania (U.S.), 2010. 5p.

[16] DEUTSCHES INSTITUT FÜR NORMUNG e. V. (DIN) Prüfung von Kautschuk - Shore A und Shore D - Härte-Test - DIN 53505, Alemanha, 1988. 5p.

[17] DEUTSCHES INSTITUT FÜR NORMUNG e. V. (DIN) Prüfung von Semi-Polyurethan (PUR) Integral Schaumstoffen; Materialien für Sohlen und Schuhteile - DIN 53543, Alemanha, 1989. 4p. 
[18] PAOLI, M.A., Degradação e Estabilização de Polímeros, http://www.chemkeys.com/blog/wpcontent/uploads/2008/09/polimeros.pdf. Acessado em maio de 2017.

[19] MIGUEZ, C.Q. Influência da exposição às radiações no desempenho de um compósito de poli(cloreto de vinila) (PVC) - aplicação em estabelecimentos de saúde, Tese de D.Sc., Instituto Militar de Engenharia, Rio de Janeiro, RJ, Brasil, 2013.

[20] BALZER, P. S., VICENTE, L.L., BRIESEMEISTER, R., et al., "Estudo das Propriedades Mecânicas de um Composto de PVC Modificado com Fibras de Bananeira", Polímeros: Ciência e Tecnologia, v. 17, n. 1, pp.1-4, 2007.

[21] MADALENO, E., ROSA, D.S., ZAWADZKI,S.F., et al., "Estudo do Uso de Plastificantes de Fontes Renovável em Composições de PVC", Polímeros: Ciência e Tecnologia, v. 19, n. 4, pp.263-270, Jun. 2009.

[22] IULIANELLI, G.C.V., Preparação de compósitos PVC/pó de madeira e caracterização por ressonância magnética nuclear no estado sólido, Tese de D.Sc., Instituto de Macromoléculas Professora Eloisa Mano da Universidade Federal do Rio de Janeiro, Rio de Janeiro, Brasil, 2008.

[23] KHAN, R.A., KHAN, M.A., ZAMAN, H.U., et al., "Fabrication and Characterization of Jute FabricReinforced Reinforced”, Journal of Thermoplastic Composite Materials, v. 25, p.45-58, Fev. 2012.

[24] FELTRAN, M.B., DIAZ, F.R.V. “Compósitos de PVC Reforçados com Fibra de Vidro: Utilização de Técnicas de Processamento Convencionais da Indústria Brasileira”, Polímeros: Ciência e Tecnologia, v. 17, n. 4, p.276-283, Out. 2007.

[25] RODOLFO JUNIOR, A., SOUZA, M. A., PESSAN, L. A. "Nanocompósitos de poli (cloreto de vinila) (PVC) / argilas organofílicas", Polímeros: Ciência e Tecnologia, v. 16, n. 4, pp.257-262, 2006. 